\title{
ARTICLE
}

Cite this: DOI: $10.1039 /$ xoxxooooox

Received ooth January 2012, Accepted ooth January 2012

DOI: 10.1039/xoxxooooox

www.rsc.org/

\section{A step towards Mobile Arsenic measurement for surface waters}

\author{
C.A. de Villiers, ${ }^{a}$ M.C. Lapsley ${ }^{a}$ and E. A. H. Hall ${ }^{a *}$,
}

\section{Introduction}

Many water sources, in both developed and under-developed countries, continue to contain high levels of arsenic (As), at concentration levels far exceeding the WHO drinking water guideline value of $10 \mu \mathrm{g} / \mathrm{L} .{ }^{1}$ The chronic exposure to arsenic through the consumption of these waters has been recognised as an environmental health disaster. Ingestion of amounts in excess of the guideline is putting 100 million people at risk of cancer and other arsenic-related diseases. ${ }^{2}$ It has long been realised that the determination of the total arsenic concentration is insufficient for environmental considerations, because the bioavailability as well as the physiological and toxicological effects of arsenic depend on its chemical form. ${ }^{3,4}$ Consequently, knowledge of the speciation of arsenic in natural water is important.

It is generally accepted that trivalent arsenicals (As(III)) are more toxic than the corresponding pentavalent arsenicals $(\mathrm{As}(\mathrm{V}))^{5,6}$ The toxicity of trivalent arsenicals likely occurs through its interaction with sulfhydryl groups of cysteines in biomolecules. As(III) binding to a specific protein could block its normal capacity for binding its normal substrate(s), alter the protein's conformation and function as well as its interaction with other functional proteins leading to a deterioration in cellular functions. ${ }^{6}$
Due to the well-recognised importance of arsenic detection, an over-abundance of detection methods based on spectrometric and electrochemical methods, inductively coupled plasma-mass spectrometry, neutron activation analysis, optical spectrometric techniques, colorimetric measurement methods and biosensors have been developed, reported and reviewed..$^{3,4,7,8}$ Most of these detection techniques obtain limits of detection below the WHO arsenic guideline value. Nevertheless, a vast number of existing methods, including atomic fluorescence spectrometry (AFS), which is considered the best option for ultra-trace arsenic in water, are suitable for laboratory conditions only., ${ }^{4,9-11}$

At present, the majority of commercially available field sensing kits for arsenic are equipped with a colorimetric readout scheme. ${ }^{4}$ The best reported limit of detection with these kits is $2 \mathrm{mg} / \mathrm{L}{ }^{4,12}$ Although the colorimetric field kits are able to provide rapid results in on-site conditions, they lack sensitivity and may show weak correlation with laboratory methods. ${ }^{13}$ Scaling up to a global remote analytical method requires innovative analysis combined with mobile hardware solutions. Due to their ubiquity, connectivity, and increasing complexity and power, the field of mHealth (mobile health) has emerged around mobile phones ${ }^{14}$. The goal is to provide low cost, efficient, healthcare solutions to people around the world. There are almost 7 billion mobile phones worldwide, with enthusiastic uptake not just in the developed world, but also in 
developing countries where it is predicted that mobile phone subscriptions will soon account for $78 \%$ of the world's total ${ }^{15}$. Technologies embedded within these devices are developing fast due to high consumer demand, leading to the proliferation of 'smartphones' which include powerful processors, wireless connectivity, and sensors such as cameras, microphones, accelerometers and GPS positioning ${ }^{16}$.

Modern mobile phone technology is attractive and, potentially, distributed data networks allowing interpretation and processing of environmental data (eg arsenic levels) within the communication network itself, could enable other benefits such as water-course cartography, guiding safer consumption.

The camera within the mobile phone, offers a clear detection system. However, the intended use for mobile phone camera modules is to record pictures to be viewed by the human eye. Translating this to metrology, where an image is taken, then requires analysis either by a person (at the scene or remotely) or computationally. Bourouis et al. have developed an Artificial Neural Network algorithm which runs on a smartphone to analyse images of skin to identify cancers ${ }^{17}$, allowing examinations in remote and poor areas.

Many of these ideas make use of the RGB capabilities of the smartphone camera by providing a reasonably faithful colour representation to the viewer in a complex 2-D image. In these cases exact spectral information is not important, rather the colours demarcate different areas of the images. However, successful quantisation on a smartphone for a diagnostic has also been shown for Roche's Cardiac proBNP test $\operatorname{strip}^{18}$, and accurate yes/no readings have been shown using a mechanical attachment test strip holder for tuberculosis, HIV and malaria commercial test strips, with an app which geotags the locations and sends them to a central server for disease mapping ${ }^{19}$.

The goal now is to take the next step that goes behind the processed camera image and takes the RAW data directly from the pixels of the ccd. Without the same power of laboratory based spectroscopy tools, successful use of a portable mobile phone analytical laboratory also needs well defined optical properties for the reagents that can be matched with the phone's camera output (ie RGB). In recent years, colloidal semiconductor nanoparticles (NPs), also known as quantum dots (QDs), have emerged as fluorescent probes for the detection of analytes, including many biological, organic and inorganic species. ${ }^{20}$ With their broad absorption and narrow and tunable emission spectra, ${ }^{20-23}$ they offer a clear opportunity for compatibility with the RGB component resolution well suited to a mobile phone system. As QDs are semiconductors, absorption of a photon can excite an electron within the valence band to the conduction band creating an electron-hole pair. ${ }^{24,25}$ Recombination of the electron-hole pair results in fluorescence. The breakthrough QD papers of Chan \& $\mathrm{Nie}^{26}$ and Bruchez et $a l .{ }^{27}$ demonstrated that QDs can be made water-soluble, biocompatible and functionalised via surface modification and biconjugate techniques. Therefore, through the use of appropriate functionalization techniques, QDs have a high potential for use as highly sensitive fluorescent biomarkers, (bio)chemical probes and inorganic ion sensors in aqueous environments. ${ }^{20,22,25,28-30}$

Wang et $a l^{31}$ examined the reaction of As(III) with mercaptoacetic acid (MA)-capped CdTe, MA-capped $\mathrm{CdTe} / \mathrm{ZnS}$ and glutathione (GSH)-capped CdTe QDs. Wang et al. found that only the GSH-capped CdTe QDs showed a response to $\mathrm{As}(\mathrm{III})$ and was quenched upon adding As(III) between $375 \mu \mathrm{g} / \mathrm{L}-1900 \mu \mathrm{g} / \mathrm{L}^{31}$ These QDs did not respond significantly to other metal ions such as $\mathrm{Na}^{+}, \mathrm{Ca}^{2+}, \mathrm{Mg}^{2+}, \mathrm{Al}^{3+}$ $\mathrm{Ni}^{2+}, \mathrm{Cr}^{3+}, \mathrm{Mn}^{2+}, \mathrm{Zn}^{2+}, \mathrm{Cu}^{2+}$ and $\mathrm{Fe}^{3+} \cdot{ }^{31}$ Using similar chemistry to Wang et al. ${ }^{31}$, Butwong et $a l .{ }^{32}$ took MA-capped CdS QDs, but this required a preconcentration step which generated arsine $\left(\mathrm{AsH}_{3}\right)$, which was then reacted with the QDs in a gas diffusion unit in a concentration range of $0.08-3.20 \mathrm{mM}^{32}$ Arsine generation is the most common preconcentration technique for ultra-trace determination of arsenic, as it greatly improves sensitivity regardless of the analytical technique used. However, this imposes limitations in construction as a portable device for in situ determination of As(III). As the maximum concentration limit of As allowable in drinking water is $10 \mu \mathrm{g} / \mathrm{L}$ $(0.133 \mu \mathrm{M}),{ }^{1}$ the selectivities and limits of detection (LOD) for As, especially for trivalent arsenicals, reported using QDs for detection, without the use of preconcentration, are still not sufficiently low to be considered as a viable option for As(III) sensing in water.

The research reported herein starts with the premise that sulfhydryl groups of cysteines in peptides and proteins are highly efficient binding ligands of As(III), central to the toxicity process $^{6}$, and further examines the capacity for a sensitive As(III) determination involving a bio-inspired cysteine-containing peptide affinity ligand linked with responsive quantum dots (QDs). The approach is based on examination of the glutathione ligand, as a simple affinity unit for a QD, that could be transferred to a mobile phone based assay and consideration of its improved As(III) binding selectivity and sensitivity.

\section{Materials and Methods}

All reagents used were of analytical grade and Milli-Q water was used for dilutions. All solvents were used as supplied. QDs were acquired from PlasmaChem. Hydrophobic QDs were $\mathrm{CdSe} / \mathrm{ZnS}$ core-shell particles were supplied dry with a surfactant capping of trioctylphosphine/ trioctylphosphine oxide (TOP/TOPO). These QDs are referred to as QD630 because of their maximum emission wavelength at $630 \pm 5 \mathrm{~nm}$. Hydrophilic QDs were CdTe core particles with short mercaptocarboxylic acid capping ligands. These QDs are referred to as $\mathrm{QD}_{600}$ and $\mathrm{QD}_{550}$ referring to their maximum emission wavelength. The hydrophilic QDs were suspended in water at a concentration of $1 \mathrm{mg} / \mathrm{ml}$.

3-Mercaptopropionic acid (MPA), 3-Mercaptoundecanoic acid (MUA), N-Hydroxysuccinimide (NHS) 98\%, L-glutathione, $\mathrm{N}, \mathrm{N}$-Dimethylformamide (DMF) anhydrous $99.8 \%$, potassium chloride, potassium phosphate monobasic, potassium phosphate dibasic, Ethylenediaminetetraacetic acid disodium 
salt dehydrate (EDTA), aluminium chloride, calcium chloride, copper (II) chloride, magnesium chloride, manganese chloride, arsenic (III) chloride and iron (III) chloride were acquired from Sigma Aldrich. Nickel chloride, and cobalt chloride was acquired from Acros Organics. Zinc Chloride was acquired from Fisher Scientific. 1-ethyl-3-(3-(dimethylamino)propyl) carodiimide hydrochloride (EDC) was acquired from Fluka Analytical, Amersham. Cy5 Maleimide mono-reactive dye was acquired from GE Healthcare. All reactions took place at standard laboratory conditions.

\section{Preparation of water-soluble quantum dots}

The CdTe $\mathrm{QD}_{600}$ were used as supplied with a mercaptocarboxylic acid capping. However, the $\mathrm{CdSe} / \mathrm{ZnS}$ $\mathrm{QD}_{630}$ were hydrophobic, and consequently water-soluble ligand capping exchange procedures were performed on these QDs. The $\mathrm{QD}_{630} \mathrm{~S}$ were functionalised with different carboxythiol capping ligands, namely, l-glutathione (GSH), mercaptopropionic acid (MPA), mercaptoundecanoic acid (MUA), and a mixture of MPA and MUA in a 2:1 MPA:MUA molar ratio.

The method was adapted from Ruedas-Rama $e t a l .{ }^{28}$ and Zeng et $a .^{23}$ with the following modifications: $\mathrm{QD}_{630}$ were redispersed in chloroform at a concentration of $1 \mathrm{mg} / \mathrm{mL}$. QD ${ }_{630} \mathrm{~S}$ in chloroform were then rendered water-soluble by ligand exchange. For GSH ligand exchange, typically, $1 \mathrm{~mL} \mathrm{QD}_{630}$ in chloroform $(\sim 2.67 \mathrm{nmol})$ was used, to which a GSH solution (800 $\mu \mathrm{L}$ from a solution containing $71 \mathrm{mg}$ GSH and $20 \mathrm{mg}$ $\mathrm{NaOH}$ in $1 \mathrm{~mL}$ methanol) was added. The resulting solution was stirred at room temperature for several hours or overnight. $\mathrm{NaOH}$ solution $(1 \mathrm{M}, 0.5 \mathrm{~mL})$ was then added to extract QDs to the aqueous phase, and the chloroform layer was removed using a separation funnel. $\mathrm{NaOH}$ solution $(1 \mathrm{M}, 0.5 \mathrm{~mL})$ was added to the extracted chloroform to wash out any remaining QDs. The aqueous QD solution was then separated into 4 eppendorfs. Excess GSH was removed by two consecutive precipitation steps, using acetone to aid precipitation followed by centrifugation. The resulting $\mathrm{QD}_{630} \mathrm{~s}$ were dissolved in $1 \mathrm{~mL}$ phosphate buffer $(50 \mathrm{mM}, \mathrm{pH} 7.2)$ to produce a resulting concentration of $2.67 \mu \mathrm{M}$ QD equivalent. The capped QDs were stored at $4{ }^{\circ} \mathrm{C}$ and shielded from sunlight to prevent photodegradation.

MPA, MUA, and MPA/MUA (2:1 molar ratio) capped QDs were prepared using a similar procedure. CdSe/ZnS QDs capped with MPA, MUA, GSH and MPA/MUA (2:1 molar ratio) are referred to as $\mathrm{QD}_{630}-\mathrm{MPA}, \mathrm{QD}_{630}-\mathrm{MUA}, \mathrm{QD}_{630}-\mathrm{GSH}$ and $\mathrm{QD}_{630}-\mathrm{MPA} / \mathrm{MUA}$, respectively.

\section{Peptide Attachment to Quantum Dots}

Peptide conjugation to QDs was performed through EDC/NHS activation using the method adopted from Ruedas-Rama et $a l,{ }^{23}$ Wang et al. ${ }^{32}$, and recommended by Plasmachem ${ }^{33}$. Briefly $0.5 \mathrm{~mL}$ of $\mathrm{GSH}$ solution ( 0.08 to $80 \mathrm{mg} / \mathrm{mL}), 0.5 \mathrm{~mL}$ of EDC/NHS solution containing $40 \mathrm{mg} / \mathrm{mL}$ EDC and $4 \mathrm{mg} / \mathrm{mL}$ NHS, were mixed with $1 \mathrm{~mL}$ of carboxylated $\mathrm{QD}_{600}$ or $\mathrm{QD}_{630}$ solution $(1 \mathrm{mg} / \mathrm{mL})$ all in phosphate buffer $(50 \mathrm{mM}, \mathrm{pH} 7.2)$.
The EDC/NHS solution was prepared per batch and used immediately. After preparation of the reaction mixture, it was

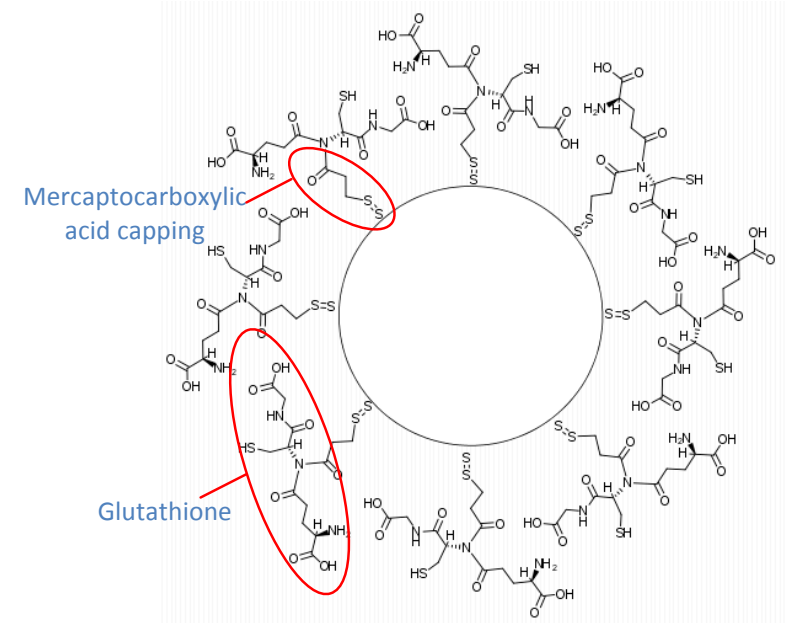

Scheme 1. Schematic of $\mathrm{QD}_{600}$-peptide conjugate product through EDC/NHS attachment of GSH to carboxylated QD surface.

stirred at room temperature for 2-4 hours and then stored at $4{ }^{\circ} \mathrm{C}$ overnight.

To ensure removal of excess unreacted reagents, the QD product was washed three times with phosphate buffer $(50 \mathrm{mM}$, $\mathrm{pH}$ 7.2) using centrifugal concentrators with a $10000 \mathrm{MWCO}$ membrane and centrifugation at $4000 \mathrm{rpm}$ for 20 minutes per wash. The final washed QD-peptide conjugated product was resuspended in $1 \mathrm{~mL}$ phosphate buffer ( $50 \mathrm{mM}, \mathrm{pH} 7.2)$, unless stated otherwise. Scheme 1 shows a schematic of the $\mathrm{QD}_{600^{-}}$ peptide conjugate product obtained. The CdTe $\mathrm{QD}_{600}$-peptide conjugate obtained is referred to as QD600-GSH in this document, while the $\mathrm{CdSe} / \mathrm{ZnS} \mathrm{QD}_{630}$-peptide obtained is referred to as $\mathrm{QD}_{630^{-}} \mathrm{GSH}-\mathrm{GSH}$.

\section{Characterisation of Successful Peptide Attachment}

Different concentrations of GSH $(0,0.08,0.8,8$ and $80 \mathrm{mg} / \mathrm{mL})$ was conjugated to equal concentrations of QDs using the method described above and reacted with a maleimide reactive dye, which has a high affinity to form sulfur bonds with the sulfhydral groups on the GSH. Formation of a bond between the fluorescent dye and the peptide attached to the QD will result in FRET as the dye comes in close vicinity to the QDs and the QD mixture is excited at a wavelength around $400 \mathrm{~nm}$.

The Amersham Cy5 maleimide mono-reactive dye was prepared by adding $50 \mu 1$ of anhydrous DMF to one pack of dye as received. The vial was flushed with nitrogen gas, capped and mixed thoroughly. After preparation of the dye, $1.5 \mu \mathrm{L}$ of the dye solution was added to each eppendorf of QD-GSH conjugates ( $1 \mathrm{~mL}$ of $\sim 1 \mathrm{mg} / \mathrm{mL}$ QD-GSH). The eppendorfs were flushed with nitrogen, capped and their contents were mixed thoroughly. The dye reaction was left to incubate at room temperature for two hours with additional mixing every 30 minutes, before being left overnight at $4{ }^{\circ} \mathrm{C}$. The 
fluorescence emission spectra of the QD-GSH-dye conjugates were scanned before washing excess dye away. The QD-GSHdye conjugates were then separated from the excess unconjugated dye by dialysis using centrifugal concentrators with a 10000 MWCO membrane and centrifugation at 4000 rpm for 20 minutes. The centrifugation washing step was performed three times, using $1 \mathrm{~mL}$ phosphate buffer $(50 \mathrm{mM}$, $\mathrm{pH}$ 7.2) for re-suspension of QDs between washing steps. The final washed product was resuspended in $1 \mathrm{~mL}$ phosphate buffer (50 mM, pH 7.2) and the fluorescence emission spectra scanned. Control emission spectra from solutions containing only GSH-dye, dye alone, and QD-GSH alone were also scanned at excitation wavelength of $400 \mathrm{~nm}$ to determine the change in the emission spectra caused by FRET.

\section{Fluorescent Intensity Measurements}

Steady-state fluorescence emission spectra were measured using a Cary-Eclipse fluorescence spectrofluorometer (Varian). The spectrofluorometer was equipped with a xenon discharge lamp $(75 \mathrm{kV})$, Czerny-Turner monochromators, two detectors (sample and internal reference), and an R-928 photomultiplier tube (PMT) with manual and automatic voltage controlled using the Cary-Eclipse software. All samples, except for the samples used for characterisation of successful peptide attachment using a maleimide reactive dye, were illuminated at an excitation wavelength of $360 \mathrm{~nm}$ and the emission was scanned from $550 \mathrm{~nm}$ to $680 \mathrm{~nm}$. Samples used for characterisation of successful peptide attachment were illuminated at an excitation wavelength of $400 \mathrm{~nm}$ and the emission was scanned from $550 \mathrm{~nm}$ to $720 \mathrm{~nm}$. The instrument excitation and emission slits as well as the PMT detector voltage was maintained constant for each batch of QD-peptide configurations. Excitation and emission slit sizes were selected at either 10 or $20 \mathrm{~nm}$ for both slits and PMT values chosen were between 580 and $800 \mathrm{~V}$. 96-well black microtiter plates from Nunc were used for measurement of most fluorescence emission spectra. Samples for the characterisation of successful peptide attachment were placed in a quartz microcell (Starna) with a light path length of $10 \mathrm{~mm}(160-\mu \mathrm{m}$ inner volume) for measurement of fluorescence emission spectra.

\section{Effect of Cations on QD Fluorescence}

The effect of various metal ions on the fluorescence intensity of $\mathrm{QD}_{630}$-MPA, QD 630 -MUA, QD $630-\mathrm{GSH}, \mathrm{QD}_{630}$-MPA/MUA and $\mathrm{QD}_{600}$ was investigated. Sets of samples were prepared by incubating $200 \mu \mathrm{L}$ of metal ion solution (ranged from $0.5 \mu \mathrm{M}$ $1 \mathrm{mM})$ in phosphate buffer $(50 \mathrm{mM}, \mathrm{pH} 7.2)$ and $100 \mu \mathrm{L}$ of 0.1 $\mathrm{mg} / \mathrm{mL}$ QD-conjugate solution ( $\sim 0.132 \mathrm{nmol}$ equivalent QD600 conjugates or $\sim 0.027 \mathrm{nmol}$ equivalent $\mathrm{QD}_{630}$ conjugates) in each well. The QD fluorescence emission response toward the metal ions at different concentrations was scanned and compared.

\section{Arsenic Calibration of Carboxylated QDs and QD-peptide Conjugates}

The response of the $\mathrm{QD}_{630}$ and $\mathrm{QD}_{600}$ fluorescence emission in the presence of various concentrations of $\mathrm{As}^{3+}$ was investigated to establish whether a calibration relationship between QD fluorescence response and the $\mathrm{As}^{3+}$ concentration exists. 200$\mu \mathrm{L}$ aliquots of $\mathrm{As}^{3+}$ ion stock solutions (ranged $5 \mathrm{nM}-30 \mathrm{mM}$ ) in phosphate buffer (50 mM, pH 7.2) were added to $100 \mu \mathrm{L}$ of QD-peptide conjugates of $\mathrm{QD}_{630}(\sim 0.026 \mathrm{nmol})$ or $\mathrm{QD}_{600}$ $(\sim 0.132 \mathrm{nmol})$ in each well. The mixtures were left to incubate for an hour before the fluorescence emission spectra were scanned. Because of the broad $\mathrm{As}^{3+}$ ion response range in all cases, logarithmic representations were made. The data, corresponding to the average of three determinations, were fitted by a standard least-squares treatment to determine a calibration curve.

\section{Mobile Phone}

The mobile telephone used for this study was the 2008 Nokia N85 smartphone which has an integrated 5 megapixel camera and runs the Symbian OS v9.3 operating system. This module was provided by the Nokia Research Centre, Cambridge, UK as a development handset. The development handset runs an inhouse application called RAWCam which allows control of camera settings which are usually automated, and gives access to the unprocessed raw data files which are produced by the camera chip. Some black-box information has also been provided on the Carl-Zeiss camera lens

In comparison with current mid/top end mobile phone cameras the N85 is now a low spec but ubiquitous camera. The specifications are summarized below:

\section{Resolution:}

CMOS sensor:

Lens:

Flash:

Focal length:

Aperture Diameter:

F-number:

Diagonal FOV:

Horizontal FOV:

Pixel pitch:

Sensor max image height (from centre to image corner): $3.5 \mathrm{~mm}$ CPU:

Connectivity:

call and SMS

Data output:

The camera in the Nokia phone is a $1 / 2.5$ " five megapixel autofocus module produced by Toshiba to the SMIA95 size specification. It comprises a 2560x1920 pixel CMOS sensor overlaid by a Bayer filter to provide colour information (see figure $5 \mathrm{~b}$ ). The task of processing image data is shared between the phone processor and the camera module itself. The CMOS chip contains circuitry behind each pixel to convert photon count to voltage, amplify this voltage, and then to digitise the information. The phone then performs various post processing algorithms to make the image more pleasing to the human eye 
and compress the image into a jpeg file. Both raw and jpeg images are produced. Raw files contain the calculated average $R, G$ and $B$ values for each pixel without any further image processing. These files are uncompressed and therefore relatively large. The jpeg files are unsuitable for use as they are not only subject to lossy compression, but the images are manipulated to create a colour balance which is pleasing to the eye rather than an accurate representation of the spectral information captured. In order to run post-processing algorithms more suitable for analytical data the pre-processed raw file was used. The Nokia development application RAWcam gives access to these raw files as well as more control over the camera. The following control and set-up was used:

The LED (Forge Europa 3mm Blue LED, manufacturer number FNL-U300B22WCSL. Peak wavelength $458 \mathrm{~nm}$. Driven by a $5 \mathrm{~V}$ power supply in series with a $75 \mathrm{Ohm}$ metal film resistor) was positioned approx $5 \mathrm{~mm}$ away from a well plate (transparent flat bottomed well strip, Greiner bio-one. Catalogue number 756070), illuminating from the side through the well wall. The filter (Edmund optics glass long pass filter 475nm, name: GG-475, $12.5 \mathrm{~mm}$ Dia. Longpass Filter. catalogue number: \#54-651) was attached to the camera module in front of the lens. The camera and filter were placed above the well looking down into it. Each QD mixture was left in the dark for $1 \mathrm{hr}$ before the image was taken.

Images used 5000s exposure, no flash, no neutral density filtering, no analogue gain, raw format images. Image analysis was performed by identifying the image area at the centre of the well selected by hand. This area is then used to analyse all images. The red/green/blue channel readings were recorded and processed separately and averaged over the defined area for each image to give the reading.

\section{Results and Discussion}

\section{QD capping ligand}

QD capping-ligand exchange using a carboxy terminated thiol,

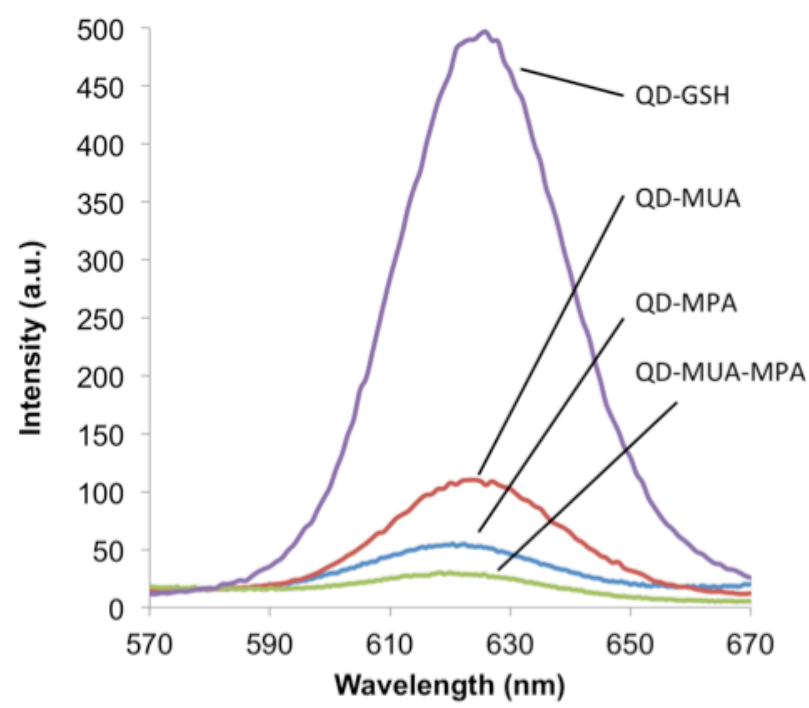

Figure 1: Fluorescence Emission Spectra of $0.09 \mu \mathrm{M}$ CdSe/ZnS QDs after attachment of each different capping ligand (Excitation at $360 \mathrm{~nm}$; PMT: 800V; Excitation Slit: 20nm; Emission Slit: 20nm).

This joumal is 2 The noyal suciety of Chemistry 2012 particularly a straight chain thiol like MUA or $\mathrm{MPA}^{23,28}$ has become a routine method for rendering water insoluble QDs both water-soluble, and displaying a surface active carboxyl, for further derivatisation. Nevertheless, this exchange is not without consequence and usually results in loss of QD emission intensity. In the case of arsenic, low detection levels are required so that loss of QD sensitivity will have an impact. Figure 1 compares the fluorescence emission spectra of $\mathrm{QD}_{630^{-}}$ MPA, QD $630^{-M U A}, \mathrm{QD}_{630^{-}} \mathrm{GSH}$, and $\mathrm{QD}_{630}$-MPA/MUA. $\mathrm{QD}_{630}$ conjugated to $\mathrm{GSH}$ retained the highest fluorescence intensity compared with the other capping ligands. It can also be noted that MUA and MPA caused hypsochromatic shifts (blue-shift) up to $10 \mathrm{~nm}$ in the wavelength of the maximum emission peak compared to that of the unfunctionalised $\mathrm{QD}_{630}$. This, combined with the fluorescence emission intensity decrease, is consistent with core degradation as a result of photo-oxidation of the QD surface and, consequently, an increasing number of surface defects and a decreasing size of the nanocrystal. ${ }^{34,35}$ Surface defects contribute to radiationless recombination of the excitons, which limits the fluorescence efficiency of the QDs. In this instance, the $\mathrm{QD}_{630}-\mathrm{GSH}$ conjugate, with a branched structure has a higher quantum yield and provides a more efficient capping ligand for the QD. This is anticipated from consideration of the QD surface curvature and the lower expected space-filling capability of a straight chain thiol versus a branched thiol. This corresponds to reports also suggesting that multidentate thiolated ligands improve stability and quantum yield. ${ }^{36}$ However, by analogy with a mechanism proposed by Tehrani et $\mathrm{al}^{37}$ for GSH on Aunanoclusters, the association of GSH at the QD surface may also be associated with oxidation of the GSH to GSSG by the QD.

In contrast to the $\mathrm{QD}_{630}$, $\mathrm{CdTe} \mathrm{QD}_{600}$ were supplied already rendered water-soluble with a carboxylated capping ligand, so there was no capacity to investigate the impact of the capping ligand.

In addition to its protective role, the capping ligand needs to impart selectivity towards $\mathrm{As}^{3+}$, appropriate for drinking water consumption. In particular this means that selectivity with respect to other metal cations. Metal binding ligands are well recognised in nature and include both macromolecular structures such as proteins, smaller oligos and chelation by organic acids, such as citrate and malate ${ }^{38}$. Taking inspiration from these biological models, the simple MUA and MPA QD functionalisation may provide a suitable analogue of the organic acid chelator, whereas complexation of $\mathrm{As}^{3+}$ through Cys-rich peptides is a feature of metallothioneins (MTs) and the enzymatically synthesized phytochelatins (PCs) ${ }^{39}$. Cadmium, lead and mercury are also known to form metal-GSH complexes, but as these ions are not commonly present in water unless there has been significant pollution $\left(\left[\mathrm{Cd}^{2+}\right]<0.0009\right.$ $\left.\mu \mathrm{M} ;\left[\mathrm{Pb}^{2+}\right]<0.024 \mu \mathrm{M} ;\left[\mathrm{Hg}^{+}\right]<0.00013 \mu \mathrm{M}\right),{ }^{1}$ they are not expected to be the cause of significant interference in the routine measurement of arsenic concentrations in surface water samples. ${ }^{40,41}$ The GSH capping ligand thus could provide the first building block towards a Cys-rich metal binding 
environment, and since it is confined at the QD surface, this may offer sufficient spatial flexibility to provide additional multidentate complexation of the metal cation. Nevertheless, $\mathrm{As}^{3+}$ ions typically form a very stable three-coordinate trigonalpyramidal complex by binding to three GSH thiol groups in a highly crosslinked phytochelatin- $\left(\mathrm{PC}_{\mathrm{n}}\right)$-like molecules. ${ }^{42}$ Furthermore, Xia et al. $^{43}$ have also shown highly selective coordination of $\mathrm{As}^{3+}$ to the three cysteine residues of $\mathrm{PC}_{3}$ molecules in the presence of $\mathrm{Cu}^{2+}$ and $\mathrm{Zn}^{2+}$ ions. Therefore, increasing GSH on the surface through peptide bonding may offer the possibility of enhancing sensitivity.

Figure $2 \mathrm{a}$ shows the relative intensity of the $\mathrm{QD}_{600}-\mathrm{GSH}$ fluorescence following increasing EDC/NHS coupled GSH. The EDC/NHS activation potentially also enables cross-linking of the QDs, so that at low concentrations of GSH in solution, aggregation was observed, suggesting that the preferred reaction results in QD cross-linking and QD-QD quenching. At higher concentrations of GSH, fluorescent intensity is partially recovered. Increase in GSH on the surface Yang et al. ${ }^{44}$ noted the molar ratio of free GSH to QDs may be in the range of about 100 to 5000 to prevent aggregation. In this instance using $13.2 \mathrm{nmol}^{\mathrm{Q} \mathrm{D}_{600}}$ no aggregation was observed for molar ratios between 1000:1 and 10000:1. As the greatest fluorescence intensity was obtained using $80 \mathrm{mg} / \mathrm{mL} \mathrm{GSH}$, this amount of GSH was used during EDC/NHS modification of the QD that were used for arsenic detection. The data in Figure 2 also suggest a red shift and broadening of the emission. While the primary determinant of emission wavelength is the QD core size, it is also influenced by surface states. QDs with a large number of surface states can show weak broad emissions ${ }^{45}$ that are often red shifted, consistent with the data recorded here. Clearly, while these $\mathrm{QD}_{630}-\mathrm{GSH}-\mathrm{GSH}$ QDs are brighter than the MUA or MPA capped QDs, the fluorescence is less intense than the $\mathrm{QD}_{630}-\mathrm{GSH}$, so that sensitivity and selectivity may require compromise.

Further insight into the GSH derivatisation can be gained using the Amersham Cy5 maleimide mono-reactive dye, which has a high affinity for the sulfhydral groups on the GSH, a FRET pair can be established between the QD and the dye (figure 2b). As can be seen in the figure, the maximum peak intensity of the QDs decreases, while that of the dye increases for the QDGSH-GSH-dye conjugates (figure 2c), consistent with a FRET pair. However, interestingly, the decrease in the QD fluorescence is focused on the longer wavelength emission so the residual maximum shows a blue shift. This probably suggests that the NHS/EDC coupling of GSH has resulted in a heterogeneous population, and caused additional surface states resulting from the peptide bonded GSH. Since the dye binds with the sulfhydral groups on GSH, it will selectively react with QDs that present the GSH for reaction.

\section{Metal ion susceptibility}

Although Callan \& Mulrooney ${ }^{46}$ and Ke et al. ${ }^{47}$ reported that introduction of a $\mathrm{ZnS}$ shell reduced the effect of metal ions on
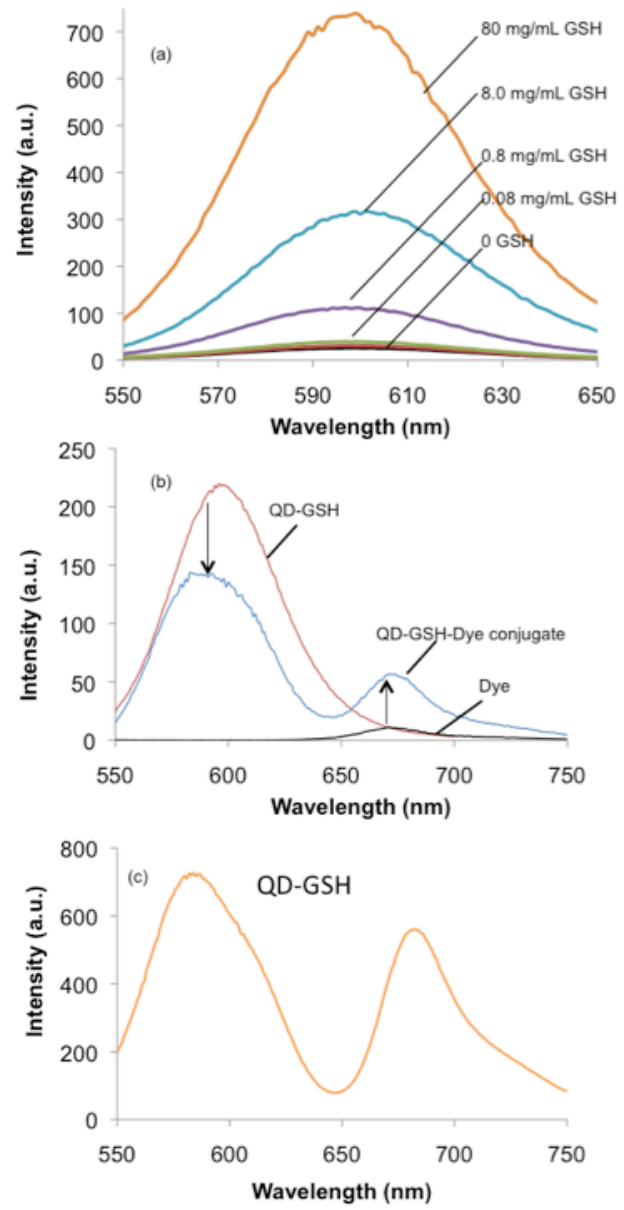

Figure 2 (a) Emission spectra of CdTe QD-GSH before and after the covalent EDC/NHS reaction with GSH in phosphate buffer (pH 7.2) (b) FRET emission spectrum of CdTe QD-GSH-Dye (Amersham Cy5 maleimide mono-reactive dye) conjugate compared to emission spectra of dye alone (and QDs alone (c) Emission spectra of the QD-GSH-GSH-dye conjugates for $80 \mathrm{mg} / \mathrm{mL} \mathrm{GSH}$ (added during EDC/NHS conjugation. (Excitation at $400 \mathrm{~nm}$; Excitation slit size: $20 \mathrm{~nm}$; Emission slit size: $20 \mathrm{~nm}$; PMT: $600 \mathrm{~V}$ )

the fluorescence intensity of QDs, since it serves as a protective layer to the core, the $\mathrm{ZnS}$ layer still offers significant activity towards metal cations. It is evident from table 1 that the $\mathrm{CdSe} / \mathrm{ZnS}$ core-shell QDs were mainly more susceptible to quenching by metal ions than the CdTe QDs (except in the case of $\mathrm{Cu}(\mathrm{II})$ ). While a robust shell is likely to increase quantum yield, and reduce environmental effects (if it is not chemically reactive) the carboxylate and GSH capping efficiency is also likely to play a part in the stability and reactivity, particularly as a metal complexing ligand. Furthermore, for the QDs compared here, the larger particle size of the CdSe/ZnS QDs (375 $000 \mathrm{Da}$ ) compared to the CdTe QDs (76000 Da), suggests a greater number of surface binding sites for interaction with cations in solution.

In terms of $\mathrm{As}^{3+}$ measurement, from table 1 interfering ions, $\mathrm{Cu}^{2+}, \mathrm{Fe}^{3+}$ and $\mathrm{Ni}^{3+}$ are of primary concern because water sources, especially those affected by acid mine drainage, may contain high concentrations, and these ions are well-known quenchers of fluorescence. $^{48}$ 


\begin{tabular}{|c|c|c|c|c|c|c|c|c|c|}
\hline \multirow[b]{2}{*}{ Metal } & \multirow[b]{2}{*}{$\begin{array}{c}\text { Average } \\
\text { Concentration } \\
\text { Reported } \\
(\mathrm{mg} / \mathrm{L})\end{array}$} & \multirow{2}{*}{$\begin{array}{c}\text { WHO } \\
\text { Drinking } \\
\text { Water } \\
\text { Limit } \\
\mathrm{mg} / \mathrm{L}(\mu \mathrm{M})\end{array}$} & \multicolumn{7}{|c|}{ Concentration $(\mu \mathrm{M})$} \\
\hline & & & CdTe QD & $\begin{array}{c}\text { QD CdTe- } \\
\text { GSH }\end{array}$ & $\begin{array}{l}\text { CdSe/ZnS } \\
\text { QD-GSH }\end{array}$ & $\begin{array}{c}\mathrm{CdSe} / \mathrm{ZnS} \\
\text { QD-GSH- } \\
\text { GSH }\end{array}$ & $\begin{array}{l}\text { CdSe/ZnS } \\
\text { QD-MUA }\end{array}$ & $\begin{array}{l}\text { CdSe/ZnS } \\
\text { QD-MPA }\end{array}$ & $\begin{array}{c}\mathrm{CdSe} / \mathrm{ZnS} \\
\text { QD- } \\
\text { MPA/MUA }\end{array}$ \\
\hline $\mathrm{Zn}(\mathrm{II})$ & $0.01-5$ & $0.01(0.15)$ & 1000 & 100 & 2.5 & 1 & 2.5 & 10 & 10 \\
\hline Co(II) & $0-0.11$ & $0.004(0.07)$ & 25 & 500 & 50 & 100 & 100 & 100 & 2.5 \\
\hline $\mathrm{Al}(\mathrm{III})$ & $0.001-1$ & $0.9(33.36)$ & 1000 & 100 & 500 & 500 & 1000 & 1 & 50 \\
\hline $\mathrm{Fe}(\mathrm{III})$ & $0.5-50$ & $2(35.81)$ & 250 & 1000 & 250 & 500 & 0.5 & 0.5 & 0.5 \\
\hline $\mathrm{Mn}(\mathrm{II})$ & $0.001-10$ & $0.4(7.28)$ & 1000 & 500 & 250 & 500 & 50 & 25 & 50 \\
\hline $\mathrm{Ni}(\mathrm{II})$ & $0.02-1$ & $0.07(1.19)$ & 50 & 250 & 100 & 25 & 100 & 0.5 & 0.5 \\
\hline $\operatorname{Mg}(\mathrm{II})$ & $1-130$ & $50(2.06)$ & 250 & 250 & 1000 & 1000 & 1000 & 100 & 1000 \\
\hline $\mathrm{Cu}(\mathrm{II})$ & $0.005-30$ & $1.5(22.9)$ & 0.5 & 0.5 & 0.5 & 1 & 0.5 & 0.5 & 0.5 \\
\hline
\end{tabular}

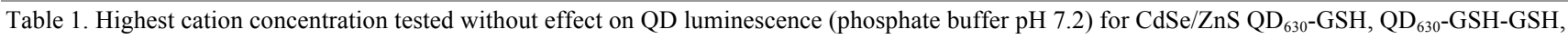
$\mathrm{QD}_{630}$-MUA, QD 630 -MPA, QD 630 -MPA/MUA and CdTe $\mathrm{QD}_{600}$ conjugates. WHO metal cation drinking water guidelines and top limit of average worldwide cation concentration ranges in water sources are also listed (WHO, 2008)

Since transition metal ions, such as $\mathrm{Fe}^{3+}$ and $\mathrm{Ni}^{2+}$, can engage in $\mathrm{d}$-d energy level transitions, the quenching observed is expected to originate from electron transfer between metal ions and QDs, resulting in nonradiative recombination. ${ }^{49}$ As seen in table 1 , $\mathrm{Cu}^{2+}$ is the most significant quencher at WHO drinking water concentrations, but $\mathrm{Cu}^{2+}$ sensitivity is reduced for $\mathrm{QD}_{630}-\mathrm{GSH}-$ $\mathrm{GSH}$, compared with the

other $\mathrm{QD}_{630} \mathrm{~s}$.

The severe quenching effect of $\mathrm{Cu}^{2+}$ on QDs is expected and has been widely reported. ${ }^{46,50-54} \mathrm{Cu}^{2+}$ ions are effective electron scavengers, preventing QD electron-hole recombination resulting in fluorescence quenching. Furthermore, at high enough concentrations, previous reports have suggested that $\mathrm{Cu}^{2+}$, can penetrate the capping layer and diffuse into the CdSe or CdTe core, ${ }^{23,55}$ where, due to the low solubility of CuSe and $\mathrm{CuTe}$, the $\mathrm{Cd}^{2+}$ in the QD lattice could be displaced by $\mathrm{Cu}^{2+}$. This is consistent with the observation for the CdTe QDs at $\mathrm{Cu}^{2+}>5 \mu \mathrm{M}$, where QD emission was quenched completely and irreversibly. $\mathrm{CdSe} / \mathrm{ZnS} \mathrm{QD}_{630}$ is also susceptible to quenching at around the same concentration, and the response curve overlays that for CdTe, except at higher concentrations where $\sim 20 \%$ fluorescence remains. Furthermore, with the additional GSH-GSH modification, overall $\mathrm{Cu}^{2+}$ susceptibility was reduced. This is consistent with the copper becoming complexed by the GSH layer, instead of penetrating into the core as described above. In an electrochemical analogue using GSH modified Au-nanoparticles, Guo et al. ${ }^{56}$ have proposed that the position of the LUMO for a metal-GSH dimer is dependent on the metal, so that electron scavenging of the QD by the metal will be influenced by the relative positions of the LUMO of the GSH-metal complex and conduction band of the QD, as well as the GSH-metal affinity kinetics. This will depend on both the metal and the GSH binding. In Singh's review ${ }^{40}$ of glutathione-metal binding it is reported that both the thiol group of the cysteine residue and the amino group of the glutamic acid are involved in complexation of $\mathrm{Cu}^{2+}$, forming octahedral complexes, with higher involvement of the amino group indicated with increase in $\mathrm{Cu}^{2+}$ concentration. This $\mathrm{Cu}^{2+}$ GSH complex defines the LUMO for scavenging of electrons from the QD. This may be consistent with the contrasting findings in the literature, that L-cysteine (rather than glutathione) capped QDs were not susceptible to $\mathrm{Cu}^{2+}$ quenching, ${ }^{49}$ because the metal complex LUMO will not facilitate electron scavenging. Singh ${ }^{40}$ points out that $\mathrm{Cu}^{2+}$ oxidation occurs rapidly with GSH, producing GSSG, but the reoxidation of GSSG is slow, so that reversibility is compromised.

In contrast, $\mathrm{Fe}^{3+}$ binding to $\mathrm{GSH}$ is proposed to involve thiolate complexation, resulting in rapid reduction to $\mathrm{Fe}^{2+}$ and dimerisation to GSSG. This may be followed by high spin $\mathrm{Fe}^{2+}$ binding, involving 5 and 6 coordinate complexes that will catalyse thiol oxidation in the presence of oxygen. The lower sensitivity towards $\mathrm{Fe}^{3+}$ observed, suggests that this metal complexation is either less favoured kinetically, or produces a LUMO that is less efficient as an electron scavenger. Overall, the likely involvement of the different metal-GSH complex LUMOs in the QD quenching mechanism will impact the degree of quenching and, dependent on the GSH structure on the QD surface, also drive the metal ion selectivity since different coordination geometry and chemistry is required for each ion.

In the case of $\mathrm{Ni}^{2+}$, Singh concluded that complexation involved the amine and carboxyl group of the glutamic acid branch. The decrease in $\mathrm{Ni}^{2+}$ quenching observed for $\mathrm{QD}_{630^{-}}$ GSH-GSH (Table 1) compared to $\mathrm{QD}_{630}-\mathrm{GSH}$ and, for QD CdTe-GSH compared with QD CdTe, may also be consistent with a raised LUMO for GSH-Ni ${ }^{2+}$ complexes with respect to the QD conduction band, thereby modulating charge separation. From Table 1 it is evident that at $50 \mu \mathrm{M}, \mathrm{Ni}^{2+}$ interference of $\mathrm{As}^{3+}$ could occur. However, as $\mathrm{Ni}^{2+}$ is not present in surface waters at concentrations greater than $17 \mu \mathrm{M}$ on average (Table 1), interference of $\mathrm{Ni}^{2+}$ on QD fluorescence is expected to be negligible.

Table 1 also identifies a strong susceptibility to $\mathrm{Zn}^{2+}$. In this instance the result is a fluorescence enhancement. It has been well reported that GSH has a high selectivity towards complex formation with $\mathrm{Zn}^{2+}{ }^{40}$ According to the idea of LUMO versus conduction band positioning, this might suggest that the LUMO 
energy level is above the conduction band, providing a protective rather than quenching role. However, an alternative interpretation of this enhancement has been proposed by Chen and Rosenzweig, who found that $\mathrm{Zn}^{2+}$ could form bridging complexes between adjacent cysteine modified QDs that form small clusters (about 3-4QDs). This resulted in an observed fluorescence increase; these explanations are not necessarily contradictory.

Thus, examination of the principles of metal-ion complex interactions with QDs, can rationalise different reports of metal ion selectivity and quenching and shows that GSH capping has
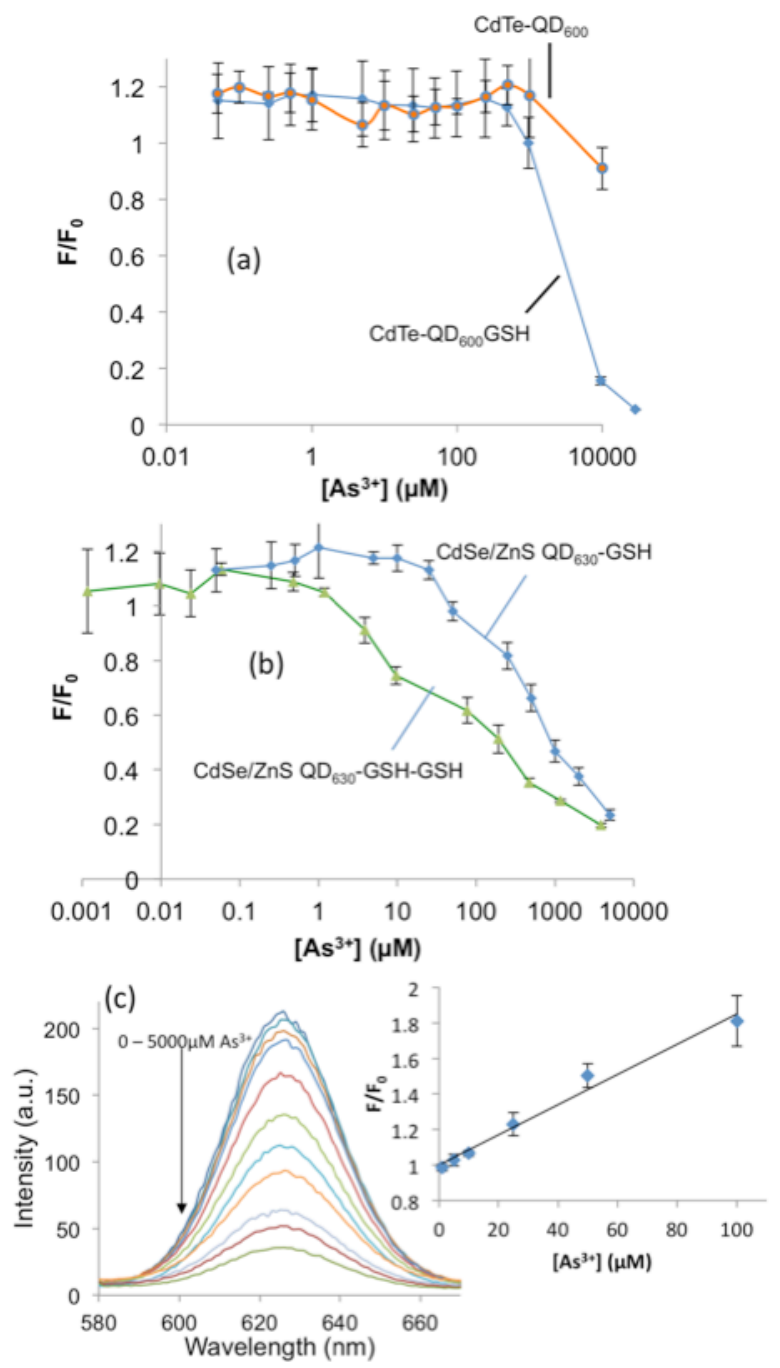

Figure 3: The normalised fluorescence maxima response of (a) carboxylated CdTe QDs compared with functionalised CdTe $\mathrm{QD}_{600}-\mathrm{GSH}$ to different concentrations of $\mathrm{As}^{3+}$; (b) $\mathrm{CdSe} / \mathrm{ZnS} \mathrm{QD}_{630}-\mathrm{GSH}$ and functionalised CdSe/ZnS QD ${ }_{630}-\mathrm{GSH}-\mathrm{GSH}$ to different concentrations of $\mathrm{As}^{3+}$. (c) Fluorescence emission spectra for $\mathrm{CdSe} / \mathrm{ZnS} \mathrm{QD}_{630}-\mathrm{GSH}-\mathrm{GSH}$ showing progressive quenching for concentrations of $\mathrm{As}^{3+}$ from $0-$ $5000 \mu \mathrm{M} \mathrm{As}^{3+}$. Insert: Stern Volmer plot for the data. . (phosphate buffer $\mathrm{pH}$ 7.2, Excitation at $360 \mathrm{~nm}$; Excitation slit size: $20 \mathrm{~nm}$; Emission slit size: $20 \mathrm{~nm}$; PMT: $800 \mathrm{~V}$ ). capacity to modulate metal ion selectivity and sensitivity depending on its surface presentation. Based on these foundations, the response of $\mathrm{As}^{3+}$ to GSH and GSH-GSH modified QDs was examined.

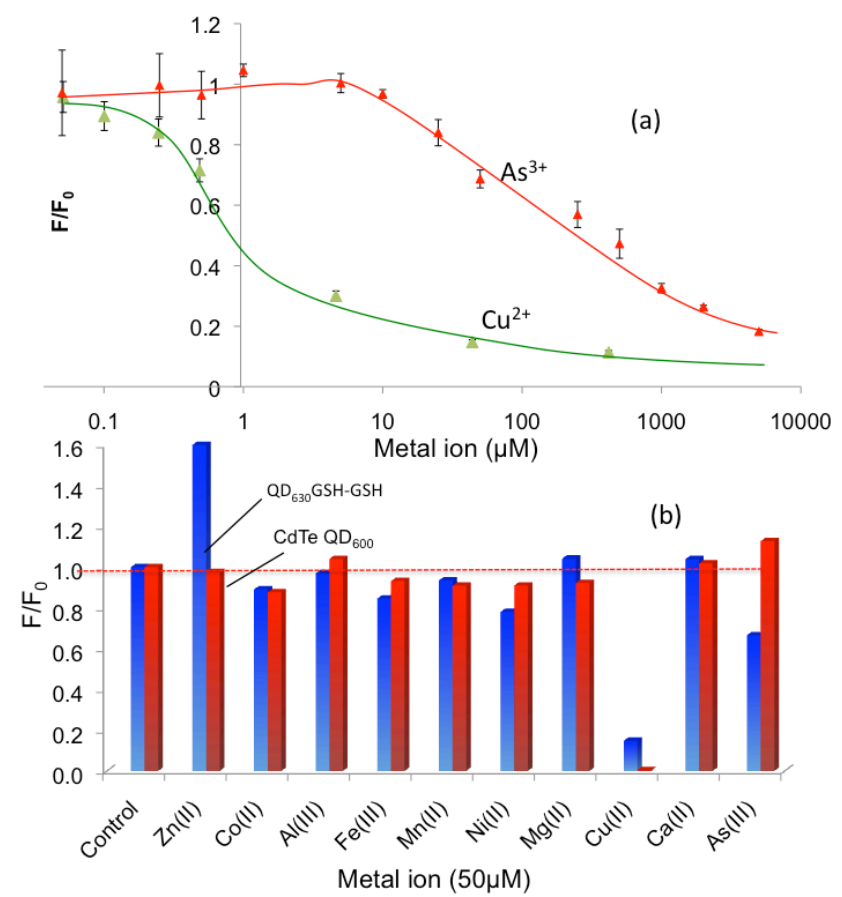

Figure 4: (a) The normalised fluorescence maxima of CdSe/ZnS QD $630-\mathrm{GSH}-$ GSH: comparison of the response by $90 \mathrm{nM} \mathrm{CdSe} / \mathrm{ZnS} \mathrm{QD}_{630}-\mathrm{GSH}-\mathrm{GSH}$ to $\mathrm{As}^{3+}$ and $\mathrm{Cu}^{2+}$ (b) Effect on the normalised fluorescence for a concentration of $50 \mu \mathrm{M}$ of different ions for $90 \mathrm{nM} \mathrm{CdSe} / \mathrm{ZnS}$ QD630-GSH-GSH and $440 \mathrm{nM}$ CdTe QD600 $(\mathrm{n}=3)$ (Excitation at $360 \mathrm{~nm}$; Excitation slit size: $20 \mathrm{~nm}$; Emission slit size: $20 \mathrm{~nm}$; PMT: $800 \mathrm{~V}$

\section{Arsenic response}

Figure 3a compares the response for CdTe QDs with and without GSH and demonstrates that only slight $\mathrm{As}^{3+}$ sensitivity can be seen in the functionalised $\mathrm{QD}_{600}-\mathrm{GSH}$. The limit of detection (LOD) $(\mathrm{S} / \mathrm{N}>3)$ lies around $\mathrm{F} / \mathrm{F}_{0}=0.78-0.80$, at a concentration of circa $1 \mathrm{mM}$ for the GSH modified QD and $>10 \mathrm{mM}$ for the unmodified CdTe QD. It is evident that the CdTe core QDs are not responsive to arsenic, although GSH functionalised CdTe QDs showed some improvement in response $>1 \mathrm{mM}$. In terms of surface water concentrations, this renders the CdTe QD unsuitable for $\mathrm{As}^{3+}$ detection.

In contrast, figure $3 \mathrm{~b}$ compares the $\mathrm{As}^{3+}$ response for $\mathrm{CdSe} / \mathrm{ZnS}$ $\mathrm{QD}_{630} \mathrm{-GSH}$ and the functionalised $\mathrm{QD}_{630} \mathrm{-GSH}-\mathrm{GSH}$. Although a clear linear quenching trend was visible, starting at an $\mathrm{As}^{3+}$ concentration of $1 \mu \mathrm{M}$, the limit of detection lies around $\mathrm{F} / \mathrm{F}_{0}=$ $0.88-0.87$ and a concentration of $\sim 150 \mu \mathrm{M}$ in the case of $\sim 90$ $\mathrm{nM} \mathrm{CdSe} / \mathrm{ZnS} \mathrm{QD}_{630}-\mathrm{GSH}$ and $\sim 10 \mu \mathrm{M}$ in the presence of $\sim 90$ $\mathrm{nM} \mathrm{CdSe} / \mathrm{ZnS} \mathrm{QD}_{630}-\mathrm{GSH}-\mathrm{GSH}$. This suggests an order of magnitude improvement compared with current field-testing systems. The GSH-GSH surface modification was tested for concentrations $>80 \mu \mathrm{g} / \mathrm{mL}$ and optimised at $80 \mathrm{mg} / \mathrm{mL}$ solution concentration during the surface reaction with the linear response to $\mathrm{As}^{3+}$ improving from $250 \mu \mathrm{M}$ to $10 \mu \mathrm{M}$ in this range. 
In mammalian metabolism, $\mathrm{As}^{3+}$ generally has a high propensity to react with cysteine thiols, particularly glutathione as the most abundant endogenous thiol, and is known to form a tridentate complex with $\mathrm{As}^{3+}$. However, unlike the endogenous glutathione, the GSH's cysteine groups are probably bonded to the QD ZnS surface and potentially not available for $\mathrm{As}^{3+}$ complexation. This leaves the $\mathrm{As}^{3+}$ in competition at the $\mathrm{ZnS}$ QD surface. This is in contrast with the $\mathrm{QD}_{630^{-}} \mathrm{GSH}-\mathrm{GSH}$, where the outer coating of GSH is attached via a peptide bond, leaving thiol and amide chemistry for metal complexation. Furthermore the thicker GSH layer may achieve better phytochelatin (PC) mimicry for $\mathrm{As}^{3+}$ binding. ${ }^{57}$ Consequently, there are GSH sulfhydral groups on the surface of the QD which are expected to have a high affinity towards $\mathrm{As}^{3+}$ binding. ${ }^{6,43}$ According to Shen et al. ${ }^{6}$, trivalent arsenic binds to three or four cysteine residues far more stably and selectively than one or two residues. There are various possible mechanisms that may be connected with the quenching. Unlike $\mathrm{Cu}^{2+}, \mathrm{As}^{3+}$ is not expected to be a good oxidant of GSH. Indeed, $\mathrm{As}^{3+}$ affinity is reversible, whereas with $\mathrm{Cu}^{2+}$ it is mostly irreversible. This suggests that there is not a resultant redox electron exchange with the QD. However, the $\mathrm{As}^{3+}$ complex formed with the GSH thiol and amide may place the LUMO of a GSH(n)-As ${ }^{3+}$ complex below the QD conduction band to allow electron transfer and thus quenching. In the design of an affinity ligand modified QD for metal-ion detection, both the kinetics of the affinity ligand and the LUMO of the resulting complex need to be taken into account. In this context, other peptide sequences might reveal greater sensitivity to other ions in figure $4 \mathrm{~b}$, even though they do not show a response with GSH surface modification.

Depending on the balance between metal-GSH affinity kinetics and the quenching mechanism, the behaviour will be different. The quenching of the QD excited state may be limited by collision with a quencher (the dynamic mechanism) or by a static mechanism arising from charge transfer (or electron tunnelling) or the overlap of molecular orbitals. Metal ion quenching typically involves electron transfer to the metal/metal complex, which might be expected to result in a non-linear Stern Volmer plot, as seen with many other semiconductor nanoparticles ${ }^{28-31}$. However, for the "metalloid", arsenic, we consider this unlikely in this instance because of the overlay of GSH ligand binding kinetics. Indeed, a characteristic Stern-Volmer plot emerges (figure 3c). The 'dynamic' behaviour seen here may be indicative of the equilibrium binding between the GSH and $\mathrm{As}^{3+}$ limiting the response rather than static electron transfer between QD and metal complex. The sensitivity of $\mathrm{QD}_{630}-\mathrm{GSH}-\mathrm{GSH}$ to $\mathrm{As}^{3+}$ is indicated by a Stern-Volmer coefficient of $\mathrm{K}=8.5 \times 10^{3} \mathrm{M}^{-1}$.

\section{Capacity for Arsenic detection in water}

\section{LABORATORY DETECTION}

Figure 4a compares the response of the QD630-GSH-GSH for $\mathrm{Cu}^{2+}$ and $\mathrm{As}^{3+}$. As expected this highlights the issue of copper interference. Despite the generally good selectivity toward $\mathrm{As}^{3+}$ with this GSH layer, zinc and copper are also clear responders (figure 4b). In nature, binding of copper and arsenic regularly occur at similar sites, so that total selectivity is unlikely. In the case of zinc, the water levels anticipated do not present a problem. Copper is an essential dietary mineral, with recommended intake $2-3 \mathrm{mg}$ /day and maximum $10 \mathrm{mg} /$ day, so it is not a particularly critical problem in drinking water. According to WHO, EPA and the Bangladesh standard, the maximum permissible limit for drinking water is 1500,1300 and $1000 \mu \mathrm{g} / \mathrm{L}$, respectively. In western drinking water, the prime source of copper arises from copper pipes, but various natural sources in different parts of the world do have measurable copper levels. For example, Balu River Bangladesh 3.81 - $19.99 \mu \mathrm{g} / \mathrm{L}$; Mississippi River, $21.5 \mu \mathrm{g} / \mathrm{L}$; Yangtze River, $7.31 \mu \mathrm{g} / \mathrm{L}$; Indus River, Pakistan $>10 \mu \mathrm{g} / \mathrm{L}^{58}$; all are much lower than the permissible limit. Thus, assuming a typical maximum level in the region of $\sim 20 \mu \mathrm{g} / \mathrm{L}(0.3 \mu \mathrm{M})$, then from figure 4 , this corresponds to up to $20 \%$ quenching by $\mathrm{Cu}^{2+}$.

Figure $4 \mathrm{~b}$ also shows the same array of metal ion responses for the CdTe QDs, where excellent selectivity for copper is demonstrated. Thus, used in conjunction with the $\mathrm{QD}_{630}-\mathrm{GSH}-$ GSH, the CdTe QD provides an option for a copper "baseline", as a way to validate the integrity of the arsenic assay in the presence of copper cross reactivity, so long as the arsenic determination remains sufficiently sensitive to achieve the WHO recommended levels. This is explored further in a mobile phone assay system.

\section{Mobile Arsenic}

As discussed earlier, the majority of commercially available field sensing kits for arsenic are equipped with a colorimetric readout scheme ${ }^{4}$. This makes the methodology for these, as well as the QD method described here, ideally suited for smart phone camera technology. Although the camera sensor only gives RGB component readings for each pixel rather than a detailed spectral readout, spatial encoding can instead be used for wavelength spectroscopy.

Figure $5 \mathrm{~b}$ shows the transmittance profile for the red, blue green and infra-red filters in the Nokia N85 phone camera. The RGB output of the phone camers can be predicted and calibrated using a spectrum recorded from incident light and the data in figure 5b. Figure 5a shows the spectrally predicted RGB signals compared with the rawcam image data taken from the N85 camera. A reasonable match can be seen, at least at these wavelengths.

From knowledge of the camera filter properties, we can design the QD wavelength to give output in a particular RGB channel. Ideally, as with a normal spectrophotometric assay, maximum wavelength separation is desirable. Figure $5 \mathrm{c}$ shows a mixture of the $\mathrm{QD}_{630}-\mathrm{GSH}-\mathrm{GSH}$ and CdTe $\mathrm{QD}_{560}$, where good wavelength separation is indicated. Reference to figure $5 \mathrm{~b}$, suggests that overall, this should lead to a CdTe $\mathrm{QD}_{560}$ dominated green channel, a $\mathrm{QD}_{630}-\mathrm{GSH}-\mathrm{GSH}$ dominated red channel and a blue referencing channel. Unfortunately, the CdTe $\mathrm{QD}_{560}$ were unstable and the signal intensity diminished rapidly with time. In contrast, both $\mathrm{CdTe} \mathrm{QD}_{600}$ and $\mathrm{QD}_{630^{-}}$ GSH-GSH gave viable output but without anticipated good 
spectral separation. Nevertheless, figure 5e shows the $\mathrm{QD}_{630^{-}}$ (a)
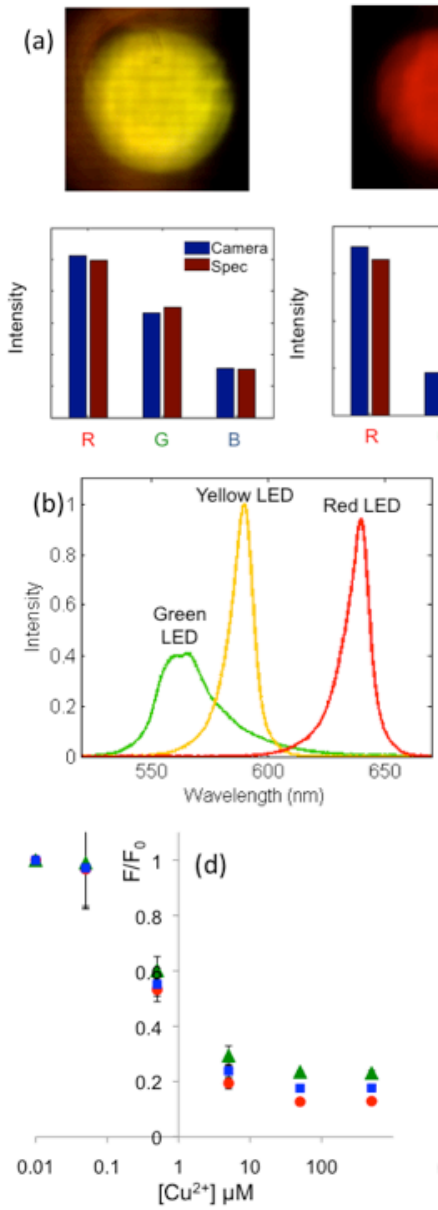
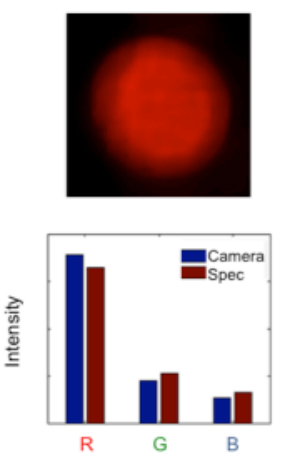
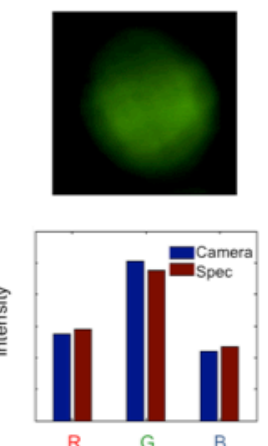
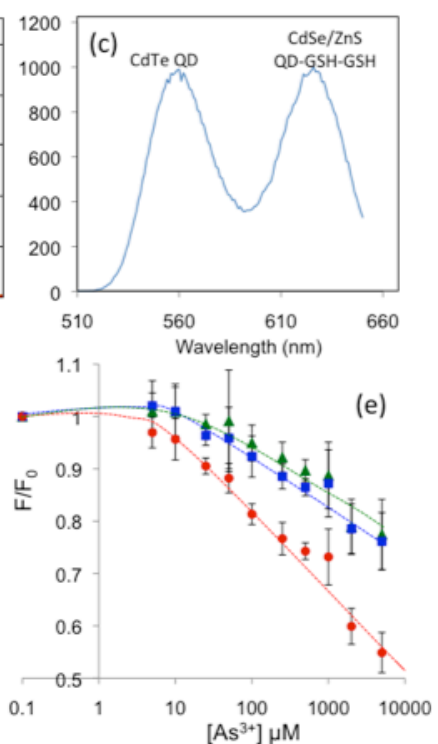

(e)

Figure 5: Data from the Nokia N85 mobile phone camera. (a) Camera output for different spectral images and the RGB raw output, together with predicted output based on filter transmission data; (b) Spectra for the green, red and yellow LEDs. (c) Emission spectrum for mixture of CdTe $\mathrm{QD}_{560}$ and $\mathrm{QD}_{630}$-GSH-GSH showing spectral separation. (d) RGB response from CdTe $\mathrm{QD}_{600}$ for $\left[\mathrm{Cu}^{2+}\right]$. (e) RGB response from $\mathrm{QD}_{630}-\mathrm{GSH}-\mathrm{GSH}$ for $\left[\mathrm{As}^{3+}\right]$.

GSH-GSH RGB response to arsenic, is consistent with the data collected with a fluorometer (figures 3 and 4) and broadly confirms the design expectation on RGB output, from examination of the output from the yellow and red LEDs (figure $5 \mathrm{~b}$ ). It can also be seen that $\left[\mathrm{As}^{3+}\right]$ can be measured either directly from the absolute output from the red channel or as the difference between the red and green or blue channels. Of special note, compared with the fluorometer data, the lowest detection level is $\leq 5 \mu \mathrm{M}$, a slight improvement compared with the lab-based fluorometer method.

The detection integrity in the presence of copper interference can be checked from the CdTe $\mathrm{QD}_{600}$ (figure 5d) data, which also mimics the fluorometer data in figure $4 \mathrm{~d}$. These data show almost the same output from all RGB channels. This was predicted for red and green, but the coincident output from the blue channel takes into account of the additional longpass filter used, and suggests a higher relative transmittance in the blue channel, for this camera at this wavelength. However, these data also demonstrate the significant potential to allow QDs, even with closely aligned emission wavelength to be separated according to their relative and absolute RGB output.

From the experimental mobile phone data obtained in figure $5 \mathrm{c}$ and $5 \mathrm{~d}$ arsenic measurement can be computed against a copper corrected baseline (figure 6). The figure predicts that using the CdTe $\mathrm{QD}_{600} / \mathrm{QD}_{630}$-GSH-GSH combination and a mobile phone camera, arsenic can be measured in the presence of copper, even at a typical maximum river water $\mathrm{Cu}^{2+}$ level in the region of $\sim 20 \mu \mathrm{g} / \mathrm{L}(0.3 \mu \mathrm{M})$.

\section{Conclusion}

According to British Geological Survey ${ }^{59}$, 35 million Bangladeshi people use drinking water with arsenic concentration exceeding the national standard $(50 \mu \mathrm{g} / \mathrm{L})$ and 57 million people are exposed to concentrations exceeding the World Health Organization (WHO) guideline value of 10 $\mu \mathrm{g} / \mathrm{L}^{60}$. Although arsenic estimation in the laboratory achieves levels of detection capable of measurement of arsenic at $10 \mu \mathrm{g} / \mathrm{L}$, on site portable measurement is typically an order of magnitude less sensitive, or requires preconcentration. Furthermore, potentially portable assay methods often show cross reactivity, particularly with copper, which is also an essential dietary element. Some of these methods have adopted cysteine-rich ligands for $\mathrm{As}^{3+}$ binding, but have found that the same ligands can bind other metals and thus reduce the selectivity. Similar, effects are found in nature where subtle spatial presentation of the affinity groups can play a significant role in the outcome. For example, $\mathrm{As}^{3+}$ ions typically form a very stable three-coordinate trigonal-pyramidal complex by binding to three GSH thiol groups in a highly crosslinked phytochelatin- $\left(\mathrm{PC}_{\mathrm{n}}\right)$-like molecules. ${ }^{42}$ However, GSH can bind

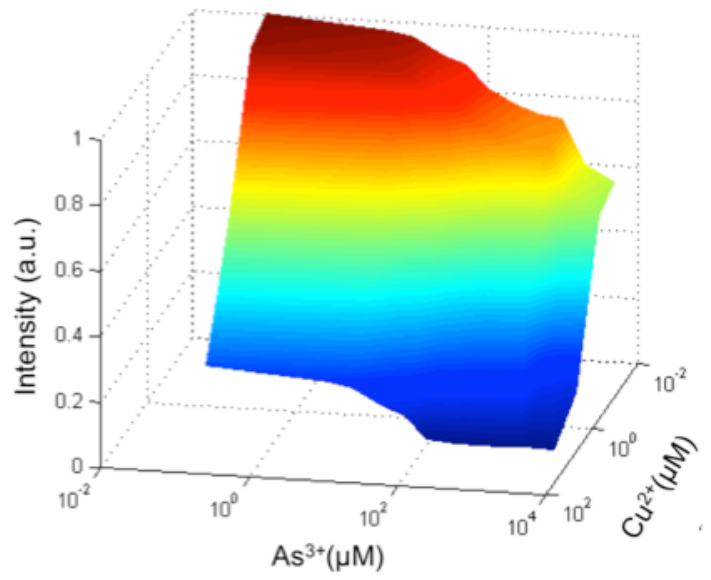

Figure 6: $\mathrm{QD}_{630}-\mathrm{GSH}-\mathrm{GSH}$ response to $\left[\mathrm{As}^{3+}\right]$ and $\left[\mathrm{Cu}^{2+}\right]$. Data from CdTe $\mathrm{QD}_{600}$ and $\mathrm{QD}_{630}-\mathrm{GSH}-\mathrm{GSH}$ are used to compute the $\mathrm{QD}_{630}-\mathrm{GSH}-$ GSH response to $\left[\mathrm{As}^{3+}\right]$ in the presence of $\left[\mathrm{Cu}^{2+}\right]$. The $\mathrm{Cu}^{2+}$-selective response from $\mathrm{CdTe} \mathrm{QD}_{600}$ ( $\mathrm{R}, \mathrm{G}$ or $\mathrm{B}$ channel) provides the input to calculate the red channel response to $\mathrm{Cu}^{2+}$ on $\mathrm{QD}_{630}-\mathrm{GSH}-\mathrm{GSH}$. This provides the baseline for the $\left[\mathrm{As}^{3+}\right]$ measurement.

metals through the amine and carboxyl groups as well as the 
thiol and thus the presentation of these groups can alter the affinity for a particular method. By paying attention to the presemtation of free sulfhydryl on the surface of a $\mathrm{CdSe} / \mathrm{ZnS}$ $\mathrm{QD}$, this work has demonstrated better $\mathrm{As}^{3+}$ selectivity ans sensitivity than reported previously. Furthermore, CdTe QDs could be prepared which showed no As ${ }^{3+}$ sensitivity, but were selective towards $\mathrm{Cu}^{2+}$, thereby offering the possibility of a baseline measurement for copper. Using the QDs as the analytical element had the benefit of a narrow emission fluorescence, which could be resolved using a reasonably low specification mobile phone camera, by direct processing of the raw pixel data. Surprisingly, by using separate processing for R, $\mathrm{G}$ and $\mathrm{B}$ channels, even QDs as close in emission maximum as 630 1nd 600, showed distinct intensity data. It could be demonstrated that taking copper specific data from the CdTe QDs produced a background 'copper-signal' for the GSH-GSH modified CdSe/ZnS QDs, that, in principle would enable arsenic measurement to be made on a mobile phone, even in the presence of copper at the highest recorded levels in some large rivers around the world. With the significant increase in resolution now available in smart phone cameras, it is possible to consider that such portable analysis is now feasilble.

\section{Acknowledgements}

Nokia Research Centre, Cambridge, UK provided the 2008 Nokia N85 smartphone as a development handset.

\section{Notes and references}

${ }^{a}$ Institute of Biotechnology, Department of Chemical Engineering and Biotechnology, University of Cambridge, Tennis Court Road, Cambridge, CB2 1QT, UK.

\section{References}

1 World Health Organization (WHO), Guidelines for Drinking-water Quality, WHO Press, Geneva, 4th edn., 2011.

2 P. Bhattacharya, A. H. Welch, K. G. Stollenwerk, M. J. McLaughlin, J. Bundschuh, and G. Panaullah, Sci. Total Environ., 2007, 379, 109.

3 Z. Gong, X. Lu, M. Ma, C. Watt, and X. C. Lee, Talanta, 2002, 58, 77.

4 D. Q. Hung, O. Nekrassova, and R. G. Compton, Talanta, 2004, 64, 269.

5 A. Mizumura, T. Watanabe, Y. Kobayashi, and S. Hirano, Toxicol. Appl. Pharmacol., 2010, 242, 119-25.

6 S. Shen, X.-F. Li, W. R. Cullen, M. Weinfeld, and X. C. Le, Chem. Rev., 2013, 113, 7769.

7 R. Feeney, Talanta, 2002, 58, 23.

8 J. Ma, M. K. Sengupta, D. Yuan, and P. K. Dasgupta, Anal. Chim. Acta, 2014, 831C, 1.

9 X. Wang, Y. Lv, and X. Hou, Talanta, 2011, 84, 382.

10 R. Liu, P. Wu, M. Xi, K. Xu, and Y. Lv, Talanta, 2009, 78, 885.

11 D. Sánchez-Rodas, W. T. Corns, B. Chen, and P. B. Stockwell, J. Anal. At. Spectrom., 2010, 25, 933.

12 I. Jaunakais, Int. Environ. Technol., no. 12, 2002.
13 S. M. Shahidullah, M. T. M. M. Rahman, D. Mukherjee, M. K. Sengupta, U. K. Chowdhury, D. Lodh, C. R. Chanda, S. Roy, M. Selim, Q. Quamruzzaman, A. H. Milton, and D. Chakraborti, Environ. Sci. Technol., 2002, 36, 5385.

14 M. Fiordelli, N. Diviani, \& P.J. Schulz, Journal of medical Internet research, 2013, 15(5), e95

15 I. T. Union, The World in 2014 ICT Facts and Figures. 2014. http://www.itu.int/en/ITUD/Statistics/Documents/facts/ICTFactsFigures2014-e.pdf

16 W. Z. Khan, Y. Xiang, M. Y Aalsalem, and Q. Arshad. IEEE Communications Surveys \& Tutorials, 2013, 15, 1.

17 A. Bourouis, A. Zerdazi, M. Feham, A. Bouchachia, Procedia Computer Science, 2013, 19, 1116.

18 P. Preechaburana, S. Maken, A. Suska. Biosensors and Bioelectronics, 2011, 26(5), 2107.

19 O. Mudanyali, S. Dimitrov, U. Sikora, S. Padmanabhan, I. Navruz, A. Ozcan Lab on a Chip, 2012, 12(15), 2678.

20 I. Costas-Mora, V. Romero, I. Lavilla, and C. Bendicho, $\operatorname{Tr} A C$ Trends Anal. Chem., 2014, 57, 64.

21 J. R. Lakowicz, Principles of Fluorescence Spectroscopy, Springer Science+Business Media, New York, 3rd edn., 2006.

22 I. L. Medintz, H. T. Uyeda, E. R. Goldman, and H. Mattoussi, Nat. Mater., 2005, 4, 435.

23 T. Zeng, Y. Hu, N. Wang, C. Xia, S. Li, Y. Zu, L. Liu, Z. Yao, Y. Zhao, and H.-C. Wu, Phys. Chem. Chem. Phys., 2013, 15, 18710.

24 J. Cox, Chem. Brit, 2003, 39, 21.

25 X. Michalet, F. F. Pinaud, L. A. Bentolila, J. M. Tsay, S. Doose, J. J. Li, G. Sundaresan, A. M. Wu, S. S. Gambhir, and S. Weiss, Science, 2005, 307, 538.

26 W. C. W. Chan and S. Nie, Science, 1998, 281, 2016.

27 M. P. Bruchez, M. Moronne, P. Gin, S. Weiss, A. P. Alivisatos, Science, 1998, 281, 2013.

28 M. J. Ruedas-Rama and E. A. H. Hall, Anal. Chem., 2008, 80, 8260.

29 X. Wang, M. J. Ruedas-Rama, and E. A. H. Hall, Anal. Lett., 2007, 40, 1497.

30 M. J. Ruedas-Rama, J. D. Walters, A. Orte, E. A. H. Hall, Anal. Chim. Acta, 2012, 751, 1.

31 X. Wang, Y. Lv, and X. Hou, Talanta, 2011, 84, 382.

32 S. Wang, N. Mamedova, N. A. Kotov, W. Chen, and J. Studer, Nano Lett., 2002, 2, 817.

33 PlasmaChem GmbH, Nanomaterials and related products catalogue, 2014, http://www.plasmachem.com/download/PlasmaChemGeneral_Catalogue_Nanomaterials.pdf.

34 V. Poderys, M. Matulionyte, A. Selskis, and R. Rotomskis, Nanoscale Res. Lett., 2010, 6, 9.

35 V. A. Krivenkov, P. S. Samokhvalov, P. A. Linkov, D. O. Solovyeva, G. E. Kotkovskii, A. A. Chistyakov, and I. Nabiev, Proc. of SPIE, 2014, 9126, $91263 \mathrm{~N}$.

36 S. Kim and M. G. Bawendi, J. Am. Chem. Soc., 2003, 125, 14652.

37 Z. A. Tehrani, Z. Jamshidi, M. J. Javan, and A. Fattahi J. Phys. Chem. A 2012, 116, 4338-4347

38 W.E. Rauser, Cell Biochem. Biophys., 1999, 31, 19.

39 C. S. Cobbett, Plant Physiol., 2000, 123, 825

40 E. J. Massaro, Handbook of Human Toxicology, CRC Press LLC, Salem, 1st edn., 1997.

41 B. K. Singh, Asian J. Chem., 2005, 17, 1. 
42 B. A. Wood and J. Feldmann, Anal. Bioanal. Chem., 2012, 402, 3299.

43 N. Xia, Y. Shi, R. Zhang, F. Zhao, F. Liu, and L. Liu, Anal. Methods, 2012, 4, 3937.

44 Z. Yang, J. Y. Ying, and Y. Zheng, US Pat., 20100117029A1, 2008.

45 C. Yang, D Awschalom, G. Stucky. Chem Mater. 2001, 13, 594.

46 J. F. Callan and R. C. Mulrooney, Phys. Status Solidi, 2009, 6, 920.

47 J. Ke, X. Li, Y. Shi, Q. Zhao, and X. Jiang, Nanoscale, 2012, 4, pp. 4996.

48 R. B. McCleskey, D. K. Nordstrom, and A. S. Maest, Appl. Geochemistry, 2004, 19, 995.

49 Y. Chen and Z. Rosenzweig, Anal. Chem., 2002, 74, 5132.

50 G. Beaune, S. Tamang, A. Bernardin, P. Bayle-Guillemaud, D. Fenel, G. Schoehn, F. Vinet, P. Reiss, and I. Texier, Chemphyschem, 2011, 12, 2247.

51 A. Bernardin, A. Cazet, L. Guyon, P. Delannoy, F. Vinet, D. Bonnaffé, and I. Texier, Bioconjug. Chem., 2010, 21, 583.

52 K. Boldt, S. Jander, K. Hoppe, and H. Weller, ACS Nano, 2011, 5, 8115.

53 J.-P. Merkl, J. Ostermann, C. Schmidtke, H. Kloust, R. Eggers, A. Feld, C. Wolter, A.-M. Kreuziger, S. Flessau, H. Mattoussi, and H. Weller, SPIE BiOS, 2014, 8955, 89551X.

54 C. Schieber, A. Bestetti, J. P. Lim, A. D. Ryan, T.-L. Nguyen, R. Eldridge, A. R. White, P. A. Gleeson, P. S. Donnelly, S. J. Williams, and P. Mulvaney, Angew. Chem. Int. Ed. Engl., 2012, 51, pp. 10523.

55 J. M. Klostranec and W. C. W. Chan, Adv. Mater., 2006, 18, 1953.

56 Z. Guo, Z. Liu, X. Yao, K. Zhang, X. Chen, J. Liu and X. Huang, Scientific Reports, 2013, 3, 3115.

57 Y. Zheng, Z. Yang, Y. Li, and J. Y. Ying, Adv. Mater., 2008, 20, 3410.

58 M. Z. Islam, A. Noori, R. Islam, M. A. Azim and S.B. Quraishi, J. Environmental Chemistry and Ecotoxicology, 2012, 4(14), 242.

59 BGS and DPHE. Arsenic contamination of groundwater in Bangladesh. Kinniburgh, D G and Smedley, P L (Editors). British Geological Survey Technical Report WC/00/19. 2001. British Geological Survey: Keyworth.

60. F Parvez, G.A. Wasserman, P. Factor-Litvak, X. Liu, V. Slavkovich, A. B. Siddique, R. Sultana, R. Sultana, T Islam, D. levy, J.L. Mey, A. van Green, K. Khan, J. Kline, H. Ahsan, J.H. Graziano, Environmental Health Perspectives, 2011, 119, 1665. 